\title{
An Experimental Study on the Effects of Oxygen in Bio-gasification - Part 2
}

\author{
Deshai Botheju, Gamunu Samarakoon, Chen Chen and Rune Bakke \\ Faculty of Technology \\ Telemark University College \\ P.O. Box 3400, Porsgrunn, Norway \\ Tel. No.: +47 45075165, e-mail: Deshai.Botheju@hit.no
}

\begin{abstract}
In order to investigate the impacts of partial aeration in anaerobic bio-gasification, a laboratory scale bioreactor (5.5 L working volume) was operated for more than 120 days duration at $35{ }^{\circ} \mathrm{C}$ under the organic loading rate of $0.33 \mathrm{~kg} \mathrm{COD} / \mathrm{m}^{3} . \mathrm{d}$ and hydraulic retention time of 33 days. Different oxygenation conditions, 0, 2.5, 5.0 and $10.1 \%$ (as \% of feed COD) induced by daily air injection after daily feeding, were tested during the course of the experiment. Oxygenation, under these operating conditions, reduced the methane generation with only a trifling effect on biogas generation. The accumulation of volatile fatty acids is extensively reduced by oxygen introduction, significantly improving the digester stability. Reduction of soluble COD and VFAs at increasing aeration level, decrease of $\mathrm{CH}_{4} / \mathrm{CO}_{2}$ ratio with increased aeration, and immediate increase of $\mathrm{CH}_{4}$ content upon reducing the aeration level at the end of the experimental duration, points out that the observed digester behaviour can be explained considering the substrate consumption by aerobic respiration activity of facultative biomass present in the reactor. Partially aerated anaerobic digestion can be a useful and a stable process for enhanced waste treatment and resource recovery.
\end{abstract}

\section{Key words}

Bio-gasification, Methane, Oxygen effects, Waste treatment

\section{Introduction}

Bio-gasification has a huge potential both as an alternative energy avenue [1-3] and a waste stabilization scheme [4-7] in the current global perspective of environmental sustainability. Positive impact on the greenhouse gas reduction $[1,3,8]$ and the potential use of digestate as a fertilizer $[1,4,8,9]$ are added advantages. Improvement of process efficiency [10] and the maintenance of stable reactor operation [7] can greatly enhance the economy and usability of this technology. Studying different options for enhanced digestion and understanding the true nature of various possible disturbances, hence, play a key role in the current research works on bio-gasification.

Impacts of limited aeration in anaerobic bio-gasification processes have been discussed in few studies carried out before. Improved solubilisation of particulate organic matter in the presence of oxygen is noted in past studies
[11-13]. Inhibitory nature of oxygen towards strict anaerobic acetate (acetogenic) and methane forming (methanogenic) organisms has also been discussed quite extensively [14-16]. Direct consumption of readily available organic matter (like monosaccharides, amino acids and volatile fatty acids (VFAs)) by aerobic respiration can also happen $[17,18]$. In the digestion of sulfur containing organic wastes, partial aeration can aid removing sulfides from the system [19-22]. This may improve the process by reducing the toxic effects of sulfides on methanogenic organisms [22] and also minimizing the corrosive and odorous $\mathrm{H}_{2} \mathrm{~S}$ formation [2, 21].

As briefly pointed out above, the oxygen can have multifaceted effects in anaerobic bio-gasification. The overall impact of aeration on the methane yield of a digestion system, thus depends on the resultant of these diverse biochemical and physiochemical reactions involving oxygen. The rates of these different pathways would eventually depend on the operating conditions of the specific digestion system, such as the nature and concentrations of substrates (soluble, particulate or other specific ingredients like S), hydraulic behavior of the reaction system (hydraulic retention time (HRT) and mixing intensity), reactor feed conditions (batch, fed batch or continuously fed) and characteristics of the inoculum used (oxygen adaptation and culture tolerance).

\section{Objectives}

The positive overall impact of limited aeration in anaerobic digestion was demonstrated in a previous experimental study, described in the part 1 of this paper [13] using batch and semi-continuously fed bioreactors. It has been shown that aeration is less advantageous in the semi-continuous mode compared to the batch feeding mode. The maximum aeration level showing a definite positive effect on methane generation was found to be 1.5 $\%$ (as \% of feed chemical oxygen demand (COD)), under the complete mixed (CSTR) semi-continuous feed mode.

The basic aim of the study described here was to further investigate the observed negative impacts in semicontinuous mode at increased aeration conditions. To 
accomplish this objective, a larger volume bioreactor (total working volume of $5.5 \mathrm{~L}$ ) facilitating extensive sampling, was operated for a longer duration (120+ days), compared to the experimental set-up used in the first study [13] where the limited reactor volume and operational time hindered more comprehensive analysis of the reactor dynamics.

\section{Methodology}

\section{A. Experimental set-up and operation}

A semi continuously (daily) fed, completely mixed glass bioreactor having a liquid volume of $3.3 \mathrm{~L}$ and a headspace volume of $2.2 \mathrm{~L}$ was operated for more than 120 days under strict anaerobic and various oxygen loaded conditions to evaluate the effects of oxygenation on the reactor performance. The inoculum used for this reactor was taken from an active mesophilic $\left(35^{\circ} \mathrm{C}\right)$ biogasification plant fed with chemically precipitated primary sludge from municipal wastewater (Porsgrunn municipality, Norway). Inoculum was initially filtered through a $0.5 \mathrm{~mm}$ wire mesh to remove any bulky particulates and then purged with $\mathrm{N}_{2}$ gas until the dissolved oxygen reading of $0.3 \mathrm{mg} / \mathrm{L}$ is obtained. A synthetic sterile substrate solution (Table 1), having a COD of $10.9 \mathrm{~g} / \mathrm{L}$, was fed once a day with an organic loading rate (OLR) of $0.33 \mathrm{~kg} \mathrm{COD} / \mathrm{m}^{3} . \mathrm{d}$ and with the HRT of 33 days. The OLR was fixed at the above value after trialling with several higher values at the beginning (<20 days - Fig. 1). The used OLR and HRT were suitable for maintaining a stable reactor operation which was an essential factor for studying the reactor dynamics disturbed by varying oxygenation conditions. Note that typical full scale CSTR biogas plants, the most common type $[10,23,24]$ adopted in many applications, are operated at $12-30$ days HRT $[8,10,24]$ often with sludge recycle. No sludge recycle is used in the experimental digester described here. Also these conditions were comparable to the conditions tested in a previous study [13], presented as the part 1 of this paper.

Table 1: Substrate composition

\begin{tabular}{l|l}
\hline Compound & Composition $(\mathrm{g} / \mathrm{L})$ \\
\hline Starch & 3.90 \\
Peptone & 3.01 \\
Yeast extract & 3.58 \\
$\mathrm{KH}_{2} \mathrm{PO}_{4}$ & 0.29 \\
$\mathrm{~K}_{2} \mathrm{HPO}_{4}$ & 0.29 \\
\hline
\end{tabular}

A temperature controlled water bath fitted with an immersion heating circulator $\left(\right.$ Julabo $\left.^{\circledR} E D\right)$ was used for incubation at $35( \pm 0.1){ }^{\circ} \mathrm{C}$. CSTR condition was established by using a magnetic stirrer $\left(I \mathrm{ka}{ }^{\circledR}\right.$ Ret $)$ placed under the reactor and the water bath (rotation speed, 375 $\mathrm{rpm}$ ). The reactor was operated under increasing oxygen loads of $0,2.52,5.04$ and $10.07 \%$ (as \% of daily feed COD) as shown in the Figure 1. During the last stage of operation reported here, the oxygen load was reversed as shown. Oxygenation was carried out by daily air injection after daily feeding. The generated biogas was collected in an aluminium layered inflatable polymeric gas sampling bag $\left(\right.$ CaliBond $\left.^{\circledR}\right)$ connected to the reactor headspace.

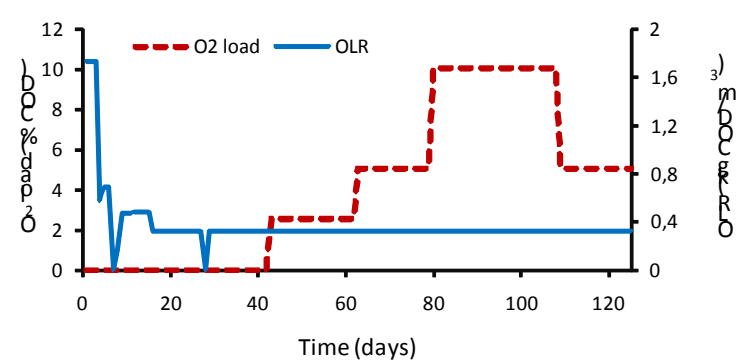

Fig. 1: Oxygen and organic loads applied to the reactor

\section{B. Reactor content analyses}

Typical anaerobic digestion parameters were measured in order to evaluate the reactor performance. Volumetric biogas generation, biogas composition, total and soluble CODs, $\mathrm{pH}$ and the volatile fatty acids of acetic, propionic, iso-butyric, butyric, iso-valeric, valeric, isocaproic, caproic and heptanoic were analysed on the samples collected on daily basis from the reactor. Total/volatile suspended solids (TSS/VSS), total/volatile solids (TS/VS) and alkalinity were also determined at regular intervals. The used analytical and sample preparation procedures are described elsewhere [13].

\section{Results}

\section{A. Biogas and methane generation}

Despite a minor reduction observed at the aeration level of $10.1 \%$, generally the biogas generation rate under different aeration stages $(0,2.5,5.0$ and $10.1 \%$.) was approximately constant at $541( \pm 67) \mathrm{ml} / \mathrm{d}$ (Fig. 2a). This unvarying biogas generation with oxygen load is consistent with the observations made before [13]. Under the increasing oxygen loads, however, methane generation was reduced (Fig. $2 \mathrm{~b}$ and Fig. 3a). Averaged methane generation rates of $377( \pm 69), 294( \pm 24), 253$ $( \pm 13)$ and $174( \pm 12) \mathrm{ml} / \mathrm{d}$ were observed at the corresponding oxygenation loads of $0,2.5,5.0$ and 10.1 $\%$. This reduction in methane generation is linear with the gradient of $-19 \mathrm{ml} / \mathrm{d}$ per $\% \mathrm{O}_{2}$. The coefficient of determination is 0.964 . The ratio of $\mathrm{CH}_{4} / \mathrm{CO}_{2}$ was decreasing through the increasing aeration (Fig. $2 \mathrm{c}$ and Fig. 3a) indicating a rise in $\mathrm{CO}_{2}$ generation. Increased $\mathrm{CO}_{2}$ generation implies increased aerobic respiration.

When the oxygen load was reduced from $10.1 \%$ to $5.0 \%$ at the last stage of reactor operation reported here (from day 109 onwards), an immediate increase in $\mathrm{CH}_{4}$ generation was observed (Fig. 2b). $\mathrm{CH}_{4} / \mathrm{CO}_{2}$ ratio was also increased immediately (Fig. 2c). This fast response may indicate that the reduced methane generation at increased aeration should, mainly, have been due to the direct substrate consumption by aerobic respiration. If the methane reduction was mainly due to the oxygen induced inhibition of the anaerobic culture, the noted positive response should have been delayed longer than observed. 

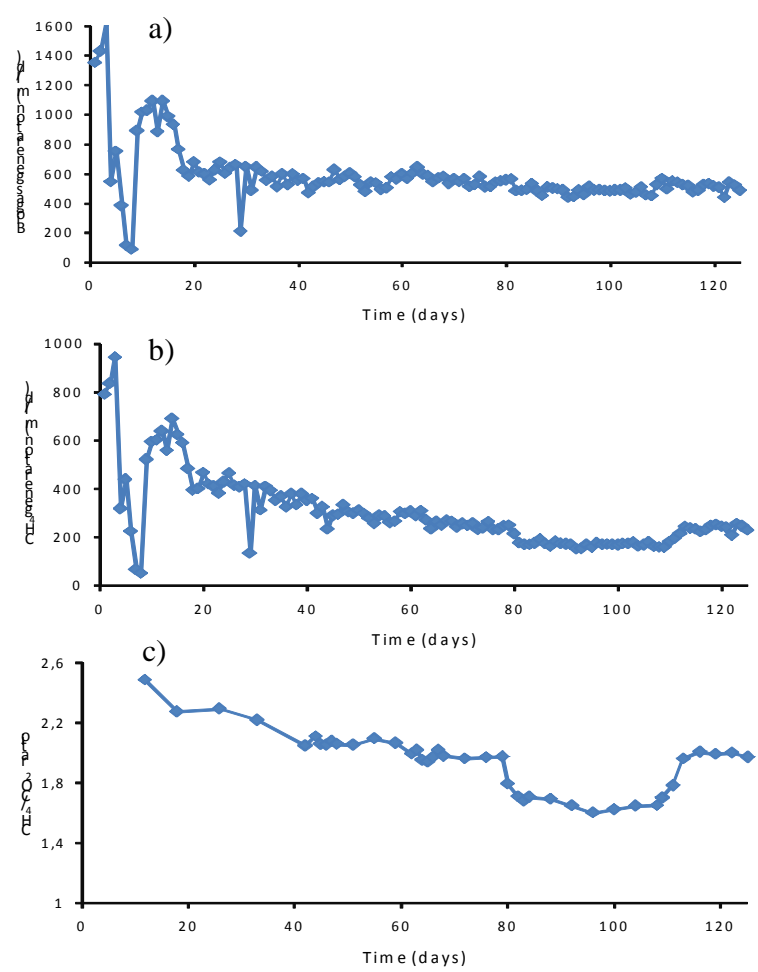

Fig. 2: Variation of biogas generation (a), methane generation (b) and $\mathrm{CH}_{4} / \mathrm{CO}_{2}$ ratio (c), during the operation of bioreactor under different oxygenation conditions.
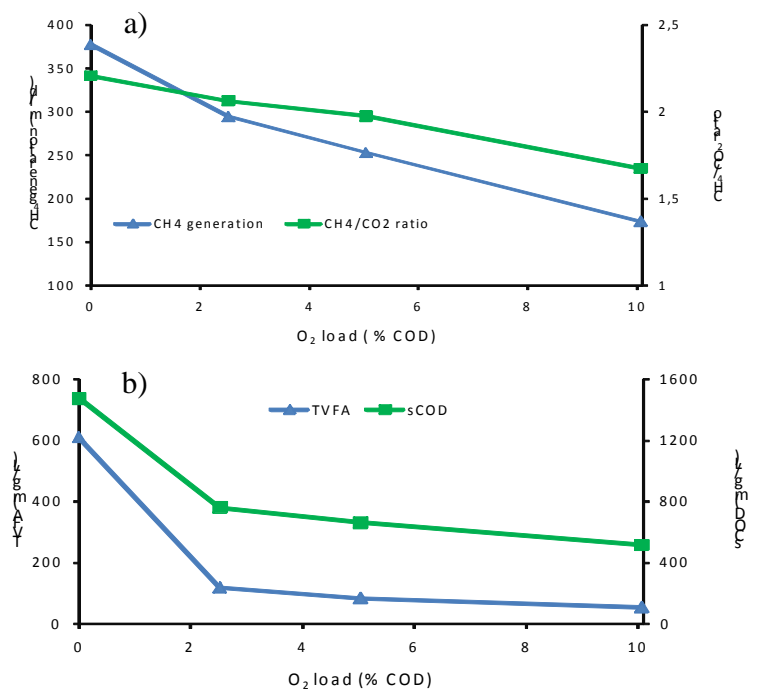

Fig. 3: $\mathrm{CH}_{4}$ generation, $\mathrm{CH}_{4} / \mathrm{CO}_{2}$ ratio (a), TVFA and sCOD (b), variations (averaged) vs. $\mathrm{O}_{2}$ load applied.

\section{B. Volatile fatty acids (VFAs)}

Oxygen introduction has a dramatic impact on the total VFAs (TVFA) content of the reactor (Fig. 3b and Fig. 4). The averaged TVFA contents of the reactor were 608 $( \pm 280), 118( \pm 56), 84( \pm 47)$ and $54( \pm 19) \mathrm{mg} / \mathrm{L}$ at corresponding oxygen loads of $0,2.5,5.0$ and $10.1 \%$ (these values represent the reactor condition just before daily feeding). An important observation is that, the variability of measured data (including VFAs and $\mathrm{CH}_{4}$ generation) is significantly reduced at increasing oxygenation. This suggests the formation of a more stable digestion system in the presence of aeration. Probably the reduction and stabilization of VFAs is the key aspect in this regard. All measured types of VFAs are reduced in considerable amounts, due to aeration (Fig. 4). The averaged contents of different species of VFAs at different oxygenated phases of reactor operation are shown in Table 2. When the aeration condition changes, from 0 to $2.5 \%$, from 2.5 to $5.0 \%$ and from $5.0 \%$ to $10.1 \%$, the percentage reductions in averaged acetic content are $81 \%, 40 \%$ and $31 \%$, respectively. The corresponding reductions for propionic are $83 \%, 22 \%$ and $11 \%$. The reduced content of propionic is especially helpful for stable digester operation [25] as propionic degrading organisms are the slowest growing and the most sensitive acetogenic organisms present in most anaerobic digester ecosystems [7].
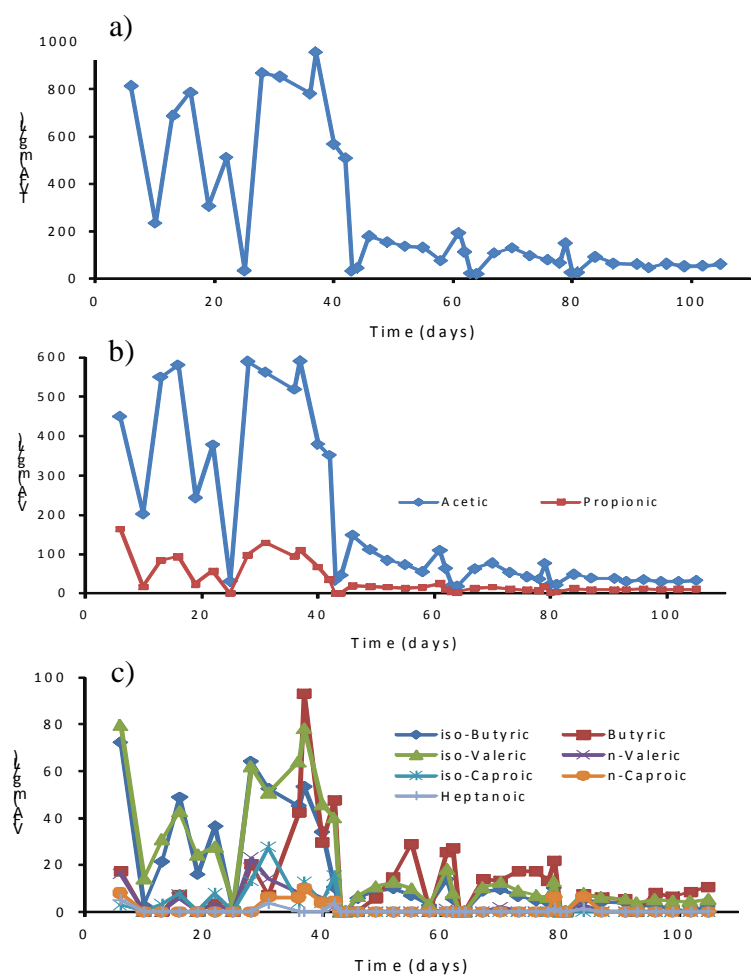

Fig. 4: TVFA (a), acetic and propionic (b) and other VFAs (c) variations during the bioreactor operation.

Table 2: Averaged VFAs (before feeding) at different aeration conditions.

\begin{tabular}{r|l|l|l|l|l|l|l|l|l}
\hline $\begin{array}{l}\mathrm{O}_{2}(\% \\
\text { COD) }\end{array}$ & acetic & popicic & i-butyric & butyric & i-valeic & n-valeric & i-caproic & n-capro & heptanoic \\
\hline 0 & 416.9 & 74.6 & 35.0 & 20.6 & 43.2 & 66 & 7.5 & 3.0 & 0.9 \\
2.57 & 80.2 & 12.9 & 5.9 & 11.3 & 7.6 & 01 & 0 & 0 & 0 \\
5.14 & 48.1 & 10.1 & 5.4 & 12.0 & 7.2 & 07 & 0 & 0.8 & 0.2 \\
10.27 & 33.0 & 9.1 & 22 & 5.2 & 4.2 & 03 & 0 & 0.6 & 0.1 \\
\hline
\end{tabular}

An abrupt reduction of the soluble chemical oxygen demand (SCOD) in the reactor was noted when the aeration was introduced (Fig. $3 \mathrm{~b}$ and Fig. 5). The variation of SCOD corresponds to the observed changes in the concentrations of VFAs (Fig. 3b). A synchronistic behaviour of TVFA and SCOD was previously observed by Mshandete et al. [18] while studying the ability of aerobic pre-treatment to enhance the mesophilic digestion of sisal pulp waste. The total COD curve shows a gradual decrease at the beginning (zero oxygen stage) and then stabilizes through the aeration stages (Fig. 5). No clear effect from the different aeration levels was noted. Increased hydrolysis and increased biomass generation due to aeration can have counterbalancing effects on tCOD. Oxidation of sCOD including VFAs by aerobic 
respiration of facultative organisms can be the likely reason for the observed oxygen effects on sCOD.

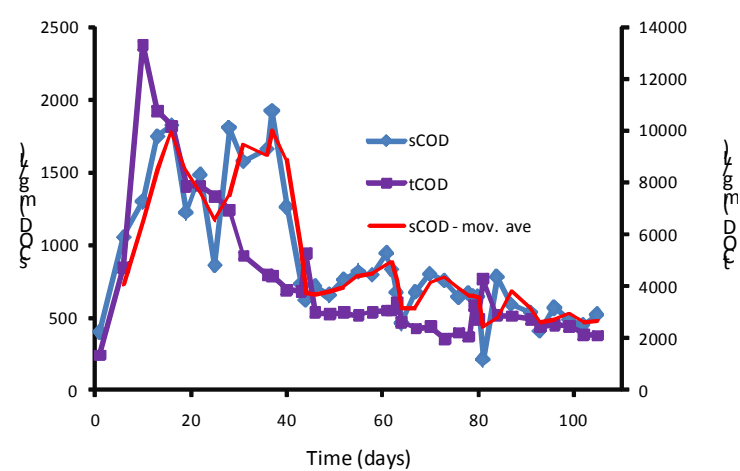

Fig. 5: Total and soluble COD variation during the reactor operation

The reactor $\mathrm{pH}$ remained constant near neutral all the time (data not shown), with no observed impact by the aeration levels. Irrespective of the variation of VFAs and the $\mathrm{CO}_{2}$ generation, the buffer capacity $(2760 \pm 76 \mathrm{mg}$ $\mathrm{CaCO}_{3} / \mathrm{L}$ ) of the reactor maintained the fixed $\mathrm{pH}$ observed.

\section{Transient behaviour}

In order to study the transient reactor behaviour at the introduction of each new aeration level, a close monitoring of the reactor has been done for 24 hours before and after the aeration/feeding point (on days 4244, 62-64, 79-81 and 108-110). Graphs for a few selected parameters during these transient periods are displayed in Fig. 6.
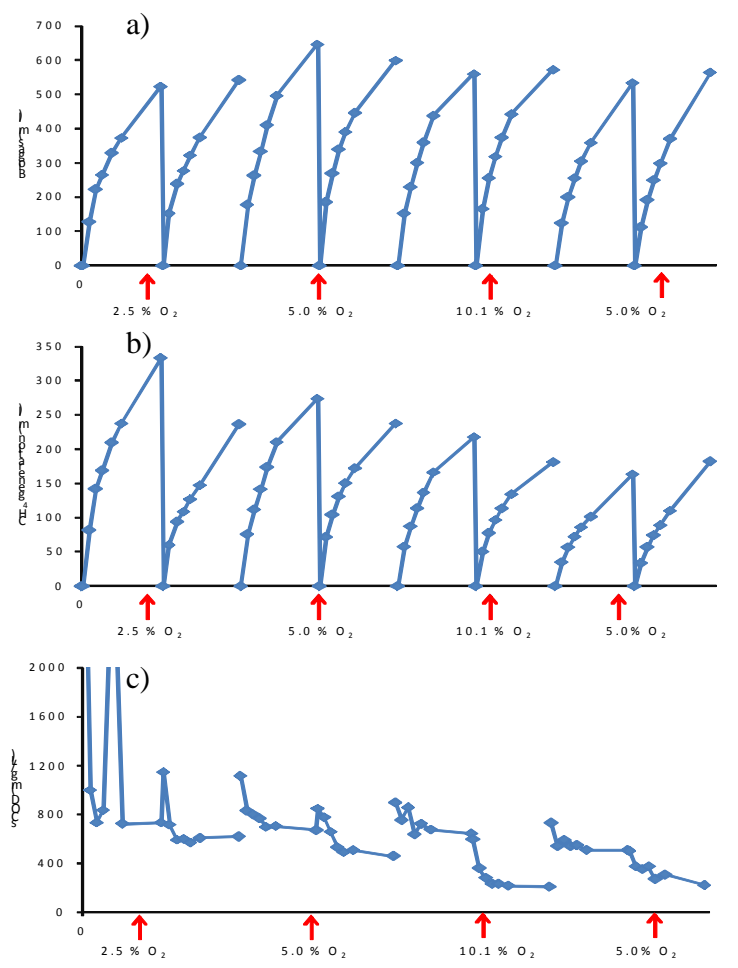

Fig. 6: Transient behaviour of biogas (a), $\mathrm{CH}_{4}$ (b) and SCOD (c) during $24 \mathrm{hrs}$., before and after introducing each new aeration level.
After observing the maximum rates just after feeding, methane and biogas generation are slowing down through the individual feeding cycles until the next feeding point is reached. Meanwhile, each step of increased aeration level resulted in a decreased cumulative methane generation in the consecutive cycles (Fig. 6b). When the aeration level decreased back to 5.0 from $10.1 \%$ at the last stage, the cumulative methane generation increased immediately in the next cycle. The total volumetric biogas generation is not affected by aeration (Fig. 6a), as described before.

Regular decreases of sCOD and VFAs are observed during each feeding cycle, after peak values near to the feeding point. This behaviour is expected in a stable semi-continuously fed reactor. Each step increase in aeration further caused reduced amounts of sCOD (Fig. $6 \mathrm{c}$ ) and VFAs, while the OLR of the reactor was constant throughout the operation. However, the reduction of SCOD and VFA at increasing aeration levels were not as prominent as the dramatic reductions observed when the condition changed from complete anaerobic to aerated operation (Fig 3b). When analysing the VFA transient profiles, it can be recognized that the oxidation of both initial hydrolytic products (monosaccharides, amino acids etc.) and subsequent VFAs are plausible. The peak TVFA contents observed after feeding were 231 $( \pm 62), 205( \pm 37)$ and $151( \pm 46) \mathrm{mg} / \mathrm{L}$ for the aeration stages of 2.5, 5.0 and $10.1 \%$, respectively. This reducing trend suggests that the formation of VFAs is suppressed by oxygen and the logical reason is the aerobic respiration on initial hydrolytic products. However, these VFA values are much higher than the just before feeding TVFA values reported in section $4 B$. This indicates that aerobic respiration on generated VFAs has also happened.

\section{Discussion}

\section{A. Rationale}

Simultaneous maintenance of both aerobic and anaerobic activities in a single bioreactor is demonstrated in this study. Methanogenic activity was sustained with no notable prolonged inhibition under the presence of oxygen in a suspended biomass system.

Decreased amounts of methane generation coupled with oxidative loss of soluble organic matter was previously observed by O'Keefe and Chynoweth [17] while experimenting on aeration effects in simulated landfill cells. Mshandete et al. [18] reported that 9 hours of aerobic pre-treatment enhanced the methane potential from mesophilic anaerobic digestion of sisal pulp waste, but noted that increasing further aeration only resulted in a significant loss of methane potential due to aerobic substrate consumption.

Any increased level of hydrolytic products by aeration, as suggested before [11-13], could have been undermined by faster aerobic respiration in the presence of increased levels of oxygen. Drastic reductions of VFAs and soluble COD was noted by Charles et al. [26] too, while studying effects of pre-aeration on thermophilic anaerobic 
digestion of organic fraction of municipal solid wastes. They [26], furthermore, found an increased enzymatic activity related to the cellulase and protease, (two hydrolytic enzymes), during the pre-aeration period.

\section{B. Waste treatment}

Considerably reduced soluble organic matter, observed due to the introduction of aeration, represent an enhanced effluent quality and an efficient treatment scheme. Due to the introduction of $2.5 \%$ aeration, the effluent SCOD was reduced to $760 \mathrm{mg} / \mathrm{L}$ from $1473 \mathrm{mg} / \mathrm{L}$ without aeration, representing a $48 \%$ improvement in effluent quality. This is at a cost of $22 \%$ reduction in methane content. At the aeration condition of $10.1 \%$, the corresponding effluent sCOD was $516 \mathrm{mg} / \mathrm{L}$ representing a $65 \%$ improvement in effluent quality, at a $54 \%$ reduction in methane generation. A cost benefit analysis may be used to choose between enhanced energy production and improved treatment. Under normal operation of anaerobic digesters, a considerable fraction of refractory COD always exits the process resisting anaerobic biodegradation [27]. To reduce this content and enhance the treatment, various means of "exotic" pre-treatment prior to anaerobic digestion have been suggested, such as thermal, ultrasonic, chemical (ozone, $\mathrm{H}_{2} \mathrm{O}_{2}$ etc.) and enzymatic hydrolysis [28-32]. The investigated aerated anaerobic digestion process can be a simple alternative solution which could especially be useful in dealing with recalcitrant, persistent and eco-toxic organic wastes. Sequential aerobic-anaerobic or anaerobic - aerobic treatment has been suggested previously for such waste streams [33, 34]. Micro-aeration assisted anaerobic treatment has been introduced for the treatment of monoethanolamine wastes generated in post combustion $\mathrm{CO}_{2}$ capture [35]. Further studies must be performed for assessing the real potential of this aeration assisted anaerobic digestion approach.

\section{Self heating capacity}

Although not scrutinized in this study, increased self heat generation due to aerobic respiration associated with an anaerobic process [26] can be helpful in elevating the digestion temperature to thermophilic conditions; hence increasing the process efficiency and methane yield [25, 28]. Thermophilic digestion $\left(\sim 55^{\circ} \mathrm{C}\right)$ further contributes towards reducing the effluent pathogenic organisms count by thermal inactivation $[25,36]$. According to one study [36], at $55{ }^{\circ} \mathrm{C}$, a holding time of $20-60 \mathrm{~min}$. can achieve complete pathogen reduction in anaerobic digester effluents. The same study [36] revealed that Escherichia coli and Salmonella spp. were not damaged by mesophilic digestion while thermophilic digestion resulted in a rapid pathogen inactivation. It is probable that aerobic and anaerobic combined ecologic environment might be further helpful in breaking pathogenic propagation cycles. Sometimes, sequential anaerobic - aerobic treatment is adopted for enhanced pathogen removal [37]. WWTP operators in certain countries are legally bound to heat up anaerobic effluents for pathogen reduction [37]. In Norway, the accepted practice is to include an upstream hygienisation stage $\left(>70{ }^{\circ} \mathrm{C},>2 \mathrm{hrs}\right.$.) for digesters treating municipal organic wastes. In that kind of situations, a part of the energy lost due to aeration and methane reduction can in fact be recovered as heat generation by aerobic respiration, requiring reduced external heat load.

\section{Sludge production}

Increased sludge production by aerobic activity [38, 39] can be a disadvantage, but the low aerations levels applied give low production. Also, the use of this biological sludge as a fertilizer/soil amendment $[1,4,8$, 9] can offset this drawback. Anaerobic digestion effectively increases the plant available nutrient content of the organic wastes [1]. Aeration can in fact aid in producing a more stable and aesthetically sound (odourless - less $\mathrm{H}_{2} \mathrm{~S}$ and VFAs) and safer (reduced pathogens) sludge compared to a complete anaerobic process. Oxygen can further be useful in fixing non biodegradable contaminants like heavy metals present in the digestates [9]. Post aeration of anaerobically digested sludge for improved $\mathrm{C}$ and $\mathrm{N}$ removal has been suggested in other studies [40].

\section{Conclusions}

Under the operating conditions tested here aeration levels of $2.5,5.0$ and $10.1 \%$ resulted in reduced methane generation proportional to the amounts of oxygen supplied. The total volumetric biogas generation was not significantly influenced by the aeration as reduced methane yield was replaced by increased $\mathrm{CO}_{2}$ yield.

Aeration has a significant impact on reducing the VFAs accumulation in the reactor, leading to a more stable digester operation.

The observed behaviour of the digester can be explained by aerobic respiration of soluble intermediate products. Oxygen inhibition of strictly anaerobic organisms appears to play a minor role.

Partial aeration assisted anaerobic digestion can be applied as a useful mean for enhanced waste treatment and safer biological sludge utilisation.

\section{Acknowledgement}

This study is funded by the Research Council of Norway. Technical support provided by Hildegunn H. Haugen is appreciated.

\section{References}

[1] M. Lantz, M. Svensson, L. Björnsson and P. Börjesson, "The prospects for an expansion of biogas systems in Sweden-Incentives, barriers and potentials", Energy Policy, vol. 35 (2007), pp. 1830-1843.

[2] K. Salomon, and E. E. S. Lora, "Estimate of the electric energy generating potential for different sources of biogas in Brazil", Biomass and Bioenergy, vol. 33 (2009), pp. 1101 1107.

[3] L. Yu, K. Yaoqiu, H. Ningsheng, W. Zhifeng and X. Lianzhong, "Popularizing household-scale biogas digesters for rural sustainable energy development and greenhouse gas 
mitigation", Renewable Energy, vol. 33 (2008), pp. 20272035.

[4] M. Berglund and P. Börjesson, "Assessment of energy performance in the life-cycle of biogas production", Biomass and Bioenergy, vol. 30 (2006), pp. 254-266.

[5] I. M. Buendía, F. J. Fernández, J. Villaseñor and L. Rodríguez, "Feasibility of anaerobic co-digestion as a treatment option of meat industry wastes", Bioresource Technology, vol. 100 (2009), pp. 1903-1909.

[6] M. J. Cuetos, X. G'omez, M. Otero and A. Mor'an, "Anaerobic digestion of solid slaughterhouse waste (SHW) at laboratory scale: Influence of co-digestion with the organic fraction of municipal solid waste (OFMSW)", Biochemical Engineering Journal, vol. 40 (2008), pp. 99 106.

[7] H. B. Nielsen, H. Uellendahl and B. K. Ahring, "Regulation and optimization of the biogas process: Propionate as a key parameter", Biomass and Bioenergy, vol. 31 (2007), pp. 820830.

[8] J.B. H. Nielsen, T. A. Seadi and P. O. Popiel, "The future of anaerobic digestion and biogas utilization", Bioresource Technology, vol. 100 (2009), pp. 5478-5484.

[9] D. Botheju, Ø. Svalheim, B. Rydtun, J. Johansen, T. K. Haraldsen and R. Bake, "Fertilizer production by digestate nitrification", In proceedings of the $12^{\text {th }}$ European Biosolids and Organic Resources Conference, Manchester, UK, November 2007.

[10] P. Kaparaju, L. Ellegaard and I. Angelidaki, "Optimisation of biogas production from manure through serial digestion: Lab-scale and pilot-scale studies", Bioresource Technology, vol. 100 (2009), pp. 701-709.

[11] J. E. Johansen and R. Bakke, "Enhancing hydrolysis with micro-aeration", Water science and Technology, vol. 53, no.8 (2006), pp. 43-50.

[12] P. S. Jagadabhi, P. Kaparaju and J. Rintala, "Effect of micro-aeration and leachate replacement on COD solubilization and VFA production during mono-digestion of grass-silage in one-stage leach-bed reactors", Bioresource Technology (2009), Article in Press,

doi:10.1016/j.biortech.2009.10.083

[13] D. Botheju, G. Samarakoon, C. Chen and R. Bakke, "An Experimental Study on the Effects of Oxygen in Biogasification - Part 1", Submitted Manuscript for the International Conference on Renewable Energies and Power Quality (ICREPQ' 10), Granada, Spain, 2010.

[14] R. E. Hungate, "A roll tube method for cultivation of strict anaerobes", Methods in Microbiology, vol. 3B (1969), pp. 117-132.

[15] W. B. Whitman, T. L. Bowen and D. R. Boone, "The methanogentic bacteria", Springer-Verlag, New York (1992), pp. 719-767.

[16] A. Conklin, R. Bucher, H. D. Stensel and J. Ferguson, "Effects of Oxygen exposure on Anaerobic digeter sludge", Water Environment Research , vol. 79, no. 4 (2007), pp. 396405.

[17] D. M. O'Keefe and D.P. Chynoweth, "Influence of phase separation, leachate recycle and aeration on treatment of municipal solid waste in simulated landfll cells", Bioresource Technology, vol. 72 (2000), pp. 55 -66.

[18] A. Mshandete, L. Börjesson, A. K. Kivaisi, S. T. Rubindamayugi and B. Mattiasson, "Enhancement of anaerobic batch digestion of sisal pulp waste by mesophilic aerobic pre-treatment", Water Research, vol. 39 (2005), pp. $1569-1575$.

[19] T. Duangmanee, "Micro-Aeration for sulfide removal in anaerobic treatment of high-solid wastewater", Presented at AgSTAR National Conference Sacramento, California, November 27-28, 2007.

[20] M. F. Polanco, I. Diaz, S. I. Pérez, A. C. Lopes and F. F. Polanco, "Hydrogen sulphide removal in the anaerobic digestion of sludge by micro-aerobic processes: pilot plant experience", Water Science and Technology, vol. 60, no. 12 (2009), pp. 3045-3050.

[21] F. P. v. Zee, S. Villaverde, P. A. Garcia, F. F. Polanco, "Sulfide removal by moderate oxygenation of anaerobic sludge environments", Bioresource Technology, vol. 98 (2007), pp. 518-524.

[22] W. Zhou, T. Imai, M. Ukita, F. Li and A. Yuasa, "Effect of limited aeration on the anaerobic treatment of evaporator condensate from a sulfite pulp mill", Chemosphere, vol. 66 (2007), pp. 924-929.

[23] R. P. J. M. Raven and K. H. Gregersen, "Biogas plants in Denmark: successes and setbacks", Renewable and Sustainable Energy Reviews, vol. 11 (2007), pp. 116-132.

[24] K. Boe, D. Karakashev, E. Trably and I. Angelidaki, "Effect of post-digestion temperature on serial CSTR biogas reactor performance", Water Research, vol. 43 (2009), pp. 669-676.

[25] M. Kim, Y. H. Ahn and R.E. Speece, "Comparative process stability and efficiency of anaerobic digestion; mesophilic vs. Thermophilic", Water Research, vol. 36 (2002), pp. 4369-4385.

[26] W. Charles, L. Walker and R. C. Ruwisch, "Effect of preaeration and inoculum on the start-up of batch thermophilic anaerobic digestion of municipal solid waste", Bioresource Technology, vol. 100 (2009), pp. 2329-2335.

[27] C. Dumas, S. Perez, E. Paul and X. Lefebvre, "Combined thermophilic aerobic process and conventional anaerobic digestion: Effect on sludge biodegradation and methane production", Bioresource Technology, vol. 101 (2010), pp. 2629-2636.

[28] I. Ferrer, S. Ponsá, F. Vázquez and X. Font, "Increasing biogas production by thermal $\left(70{ }^{\circ} \mathrm{C}\right)$ sludge pre-treatment prior to thermophilic anaerobic digestion", Biochemical Engineering Journal, vol. 42 (2008), pp. 186-192.

[29] M. R. Salsabil, A. Prorot, M. Casellasa and C. Dagot, "Pre-treatment of activated sludge: Effect of sonication on aerobic and anaerobic digestibility", Chemical Engineering Journal, vol. 148 (2009), pp. 327-335.

[30] R. Dewil, L. Appels, J. Baeyens and J. Degreve, "Peroxidation enhances the biogas production in the anaerobic digestion of biosolids", J. Hazardous Material, vol. 146 (2007), pp. 577-581.

[31] A.B. Martinez, H. Carrére, D. Patureau and J. Delgenés, "Ozone pre-treatment as improver of PAH removal during anaerobic digestion of urban sludge", Chemosphere, vol. 68 (2007), pp. 1013-1019.

[32] R. T. Romano, R. Zhang, S. Teter and J. A. McGarvey, "The effect of enzyme addition on anaerobic digestion of Jose Tall Wheat Grass", Bioresource Technology, vol. 100 (2009), pp. 4564-4571.

[33] S. Sandhya, S. Padmavathy, K. Swaminathan, Y. V. Subrahmanyam and S. N. Kaul, "Micro-aerophilic - aerobic sequential batch reactor for treatment of azo dyes containing simulated wastewater", Process Biochemistry, vol. 40 (2005), pp. 885-890.

[34] Y. Song and B. E. Logan, "Effects of $\mathrm{O}_{2}$ exposure on perchlorate reduction by Dechlorosoma $s p$. KJ", Water Research, vol. 38 (2004), 1626-1632.

[35] D. Botheju, Y. Li, J. Hovland, T. Risberg, H. A. Haugen, C. Dinamarca and R. Bakke, "Biogasification of waste monoethanolamine generated in post combustion $\mathrm{CO}_{2}$ capture", In proceedings of the $2^{\text {nd }}$ Annual Gas Processing Symposium, Doha, Qatar, 2010.

[36] S. R. Smith, N. L. Lang, K. H. M. Cheung and K. Spanoudaki, "Factors controlling pathogen destruction during anaerobic digestion of biowastes", Waste Management, vol. 25 (2005), pp. 417-425.

[37] A. O. Wagner, C. Malin, G. Gstraunthaler and P. Illmer, "Survival of selected pathogens in diluted sludge of a 
thermophilic waste treatment plant and in $\mathrm{NaCl}$-solution under aerobic and anaerobic conditions", Waste Management, vol. 29 (2009), pp. 425-429.

[38] Y. J. Chan, M. F. Chong, C. L. Law and D. G. Hassell, “A review on anaerobic-aerobic treatment of industrial and municipal wastewater", Chemical Engineering Journal, vol. 155 (2009), pp. 1-18.

[39] Y. Wei, R. T. V. Houten, A.R. Borger and D. H. Eikelboom, "Minimization of excess sludge production for biological wastewater treatment", Water Research, vol. 37 (2003), pp. 4453-4467.

[40] V. Parravicini, K. Svardal, R. Hornek and H. Kroiss, "Aeration of anaerobically digested sewage sludge for COD and nitrogen removal: optimization at large scale", Water Science and Technology, vol. 57, no. 2 (2008), pp. 257 - 264. 